\title{
GOOD FRIENDSHIPS IMPROVE OUR LIVES. BUT CAN VIRTUAL FRIENDSHIPS BE GOOD?
}

\author{
Nick Munn and Dan Weijers \\ University of Waikato \\ Gate 1 Knighton Road, Private Bag 3105, Hamilton 3240, New Zealand
}

\begin{abstract}
Good friendships improve our lives. But philosophers, psychologists, and other social scientists disagree about the nature of friendship and the value of virtual friendships. Recent technological advances and global crises highlight the importance of answering the question: can virtual friendships be good? We argue against accounts of friendship that suggest virtual relationships are necessarily deficient, focusing on rejecting the requirements of physical proximity and complete authenticity for friendship. We propose a more inclusive account of friendship that focusses on positive intentions and experiences. We also discuss examples of virtual friendships that highlight their advantages in modern times, especially their ability to promote intercultural cohesion. Finally, we suggest implications to help guide individual and collective decisions about friendship in a way that improves wellbeing.
\end{abstract}

\section{KEYWORDS}

Friendship, Virtual Friendship, Authentic, Physicality, Intention, Wellbeing

\section{INTRODUCTION}

Philosophers (Helm, 2009; Telfer, 1970), psychologists (Bayer, et al., 2018; Hojjat, et al., 2017), and others (Amichai-Hamburger, et al., 2013; Dunbar, 2018; Greco, et al., 2015) agree that friendship is an important contributor to wellbeing. But there is considerable disagreement about whether friendship is a central or peripheral component of wellbeing (Badhwar, 1993) and about what kinds of friendship are valuable (Anderson \& Fowers, 2020; Badhwar \& Dadlez, 2018). This disagreement is particularly noticeable for technologically mediated friendships (Danaher, 2019; Jeske, 2019; Munn, 2017).

Having the right kind of friendships is important for living a good life. So, understanding whether the increasing availability of virtual friendships is an opportunity or a threat is vital for making the right individual and collective decisions about the kinds of friendships to seek and encourage in modern times. Recent events have made the importance of friendship even more obvious. COVID-19 forced governments to balance the costs and benefits of physically isolating their citizens. A widely-discussed potential cost was that physical isolation would entail social isolation, or at least the degradation of social interactions to the point at which people's mental health was at risk (Courtet, et al., 2020; Marston, et al., 2020). Making the right decisions about enforced physical isolation depends on understanding both the importance of friendship for wellbeing and in what ways, if any, virtual friendships are less valuable than in-person friendships. For example, if virtual friendships are about as valuable as in-person friendships, then longer lockdowns combined with the facilitation and promotion of virtual communication technologies may be preferable to shorter lockdowns with the associated risk of higher infection rates.

In this paper, we argue that we can and do value virtual interactions and virtually mediated friendships. In the process, we propose an inclusive definition of friendship that is at odds with many recent views on the topic, highlight the benefits of virtual friendships and discuss the implications for individuals and societies. 


\section{THE NATURE OF FRIENDSHIP}

Both philosophers (Leibowitz, 2018; Nehamas, 2016) and psychologists (Apostolou, et al., 2020; Johnson, et al., 2011) argue about the nature of friendship. Many philosophical accounts of friendship follow from Aristotle's conception of friendship (Annas, 1988; Sherman 1987; Thomas, 1989). These point to the difficulty of establishing higher order friendships and claim that in virtual spaces, such friendships are more difficult or even impossible to establish (Cocking, et al., 2012; McFall, 2012; Sharp, 2012). More recent philosophical accounts (Elder, 2017; Laas, 2018; Turp, 2020), and some psychological accounts (Rawlins, 2016; Schønning, et al., 2020), argue that, while they may have some value, virtual interactions cannot be a foundation for proper friendships. This claim is most often supported by stressing virtual interactions' lack of authenticity or physicality (e.g., Fröding \& Peterson, 2012), features usually present in in-person interactions. We will argue against these restrictive accounts of friendship and the view that virtual interactions are necessarily deficient.

Certain kinds of physicality, such as supportive hand-holding and loving embraces, may be a basic human need (Nussbaum, 1995). The importance of positive physical interactions seems to be most obvious during the developmental phase from infancy to adulthood (White, 2018). For example, in a study of 53 mother-infant pairs, maternal touch was found to reduce infants' physiological reactivity to stress, reducing their cortisol levels (Feldman, et al., 2010). But notice that positive human touch can be important for our wellbeing or development without it being a necessary part of the nature of friendship. Humans have long had important friendships with people they have never met in person. Long before anyone conceived of the internet, people regularly wrote letters to their pen pals in distant lands. It is reasonable to believe that some pen pals were good friends despite never interacting in person. Therefore, it is clear that physicality is not necessary for friendship.

Fröding and Peterson (2012) argue that the people we interact with regularly online cannot become genuine friends because we cannot build authentic relationships with them. They claim that the temporally and modally restricted kinds of interactions we have online do not allow us to know the other person completely. If there are aspects of the other person we do not know about, Fröding and Peterson (2012) argue, then we cannot be friends with them. Rather, we would be under a kind of digitally enabled illusion. The person that we think we are friends with does not exist - they are a mere fragment of the complex whole of the real person you are having incomplete and inauthentic online interactions with. Fröding and Peterson's (2012) argument is based on an Aristotelian account of friendship that requires complete honesty between two virtuous agents. Both complete honesty and the high bar Aristotle sets for who can claim to be a virtuous agent, make this account of friendship entirely unrealistic. If we took these requirements seriously, then there would be very few, if any, genuine friendships. Very few of us are fully virtuous-excellent in all the important human capacities. Similarly, the vast majority of people find it difficult to be honest with ourselves, let alone others (Nuzzo, 2015). So, the argument that online friendships cannot be authentic fails because it sets the bar too high for authenticity — so high that very few if any in-person friendships would count.

Thinking more carefully about inauthenticity, it seems that our biggest worry is our friends maliciously deceiving us. Lying to a friend so as to not ruin their surprise party seems like a beneficent lie, and certainly one that the friend would not chastise us for after the party. Malicious lies, on the other hand, would cause us great distress to hear about. The friend that lies about their intentions to be a reliable house-sitter would likely lose your friendship and the opportunity to sit your house if you overheard them telling others about the raging party they are planning for at your house while you are away. So, we might not know everything about a potential friend, but as long as they have positive intentions toward us, our lack of knowledge doesn't appear to be a problem.

Working the above arguments into the general understanding of the nature of friendship, we propose an inclusive definition of friendship: Friendship is a relationship constituted by a clear majority of positive interactions between parties with positive intentions toward each other. On our view, friendships can be non-physical and even inauthentic, but only if those features do not lead to more negative interactions or negative intentions between the parties to the friendship. Our conception of friendship is distinct from others in the literature (Annas, 1987; Elder, 2017; Laas, 2018, Fröding \& Peterson, 2012) both in that it allows for shared activity via online (as well as in-person) interaction and in that it relies on intention, rather than physical interaction, to instantiate the appropriate friendship-relations. 


\section{THE VALUE OF VIRTUAL INTERACTIONS AND FRIENDSHIPS}

The risks of virtual interactions are discussed frequently, often at the expense of the potential benefits. For example, commentators frequently worry about the exposure of [usually young males] to violence via online gaming (Furlow, 2017; Huesmann, 2007) But they do not consider the opportunities such gaming can provide for leadership, friendship formation, exposure to people of different cultural and religious backgrounds, and so on.

In person, it is hard for teenagers to reach beyond their immediate social circle. A 14-16-year-old will have very few opportunities, if any, to interact in person with adults outside of their immediate family. They may talk to teachers, but the teacher-student relationship is an explicitly unequal one. Online, by contrast, the importance of age is diminished as it is often unknown. So, in many online endeavours, such as playing World of Warcraft with other guild members (Munn, 2012), these teenagers have interactions as equals with people from outside their age cohort. As age becomes irrelevant, positive virtual interactions can lead to friendships between teenagers and adults.

Virtual friendships do not rely on physical cues, and they draw from a much wider pool of potential friends than do in person friendships, which are of necessity restricted to those in physical proximity to oneself. In addition to the broader age cohort outlined above, virtual friendships also offer the benefit of exposing those engaging in them to unfamiliar cultures, beliefs, and religions. There is evidence to suggest that a major component of reducing prejudice is exposure to other cultures, so online interactions are then valuable in making us better people (Turner, et al., 2007; Vezzali, et al., 2014).

\section{IMPLICATIONS}

As virtual friendships become ubiquitous, the diversity of the average friend group is likely to expand, and in doing so, the frequency and intensity of prejudice against unfamiliar others in society will decline, simply because more people are exposed more often to others of more divergent backgrounds, than was or is the case in predominantly physical interaction. The benefit to society of this is clear. A society in which people develop a more diverse range of friendships with a heterogenous cohort of friends will be more accepting of difference than one which is restricted to traditional social structures.

If our analysis of the value of online friendships - that they are just as valuable as physical friendships, and have additional advantages which physical friendships do not-is correct, then by embracing online friendship, and by enabling and encouraging others to do so, we will lay the groundwork for a stronger, more resilient society, both in general, and in particular in times when physical interaction is curtailed by forces beyond our control. Furthermore, worries about virtual friendships taking time away from in-person friendships can be viewed as unfounded, not because it won't happen, but because it won't matter. Virtual friendships are not inferior, they are just a convenient kind of friendship.

\section{REFERENCES}

Amichai-Hamburger, Y., Kingsbury, M., \& Schneider, B. H. (2013). Friendship: An old concept with a new meaning? Computers in Human Behavior, 29(1), 33-39.

Anderson, A. R., \& Fowers, B. J. (2020). An exploratory study of friendship characteristics and their relations with hedonic and eudaimonic well-being. Journal of Social and Personal Relationships, 37(1), 260-280.

Annas, J. (1977). Plato and Aristotle on Friendship and Altruism. Mind, 86: 532-54.

Apostolou, M., Keramari, D., Kagialis, A., \& Sullman, M. (2020). Why people make friends: The nature of friendship. Personal Relationships, 28(1), 4-18.

Aristotle, Ross, W. D., \& Brown, L. (2009). The Nicomachean Ethics. Oxford University Press.

Badhwar, N. K. (Ed.). (1993). Friendship: A Philosophical Reader. Cornell University Press.

Badhwar, N. K., \& Dadlez, E. (2018). Love and friendship: Achieving happiness in Jane Austen's Emma. In E. Dadlez, (ed.) Jane Austen's Emma: Philosophical Perspectives. Oxford University Press.

Bayer, J. K., Mundy, L., Stokes, I., Hearps, S., Allen, N., \& Patton, G. (2018). Bullying, mental health and friendship in Australian primary school children. Child and Adolescent Mental Health, 23(4), 334-340.

Furlow, B. (2017). Media violence and youth aggression. Lancet Child and Adolescent Health, 1(2), 91-92. 
Cocking, D., van den Hoven, J., \& Timmermans, J. (2012). Introduction: One thousand friends. Ethics and Information Technology, 14(3), 179-184.

Courtet, P., Olié, E., Debien, C., \& Vaiva, G. (2020). Keep socially (but not physically) connected and carry on: preventing suicide in the age of COVID-19. The Journal of Clinical Psychiatry, 81(3), 0-0.

Danaher, J. (2019). The philosophical case for robot friendship. Journal of Posthuman Studies, 3(1), 5-24.

Dunbar, R. I. (2018). The anatomy of friendship. Trends in Cognitive Sciences, 22(1), 32-51.

Elder, A. M. (2017). Friendship, Robots, and Social Media: False Friends and Second Selves. Routledge.

Feldman, R., Singer, M., \& Zagoory, O. (2010). Touch attenuates infants' physiological reactivity to stress. Developmental Science, 13(2), 271-278.

Fröding, B., \& Peterson, M. (2012). Why virtual friendship is no genuine friendship. Ethics and Information Technology, 14(3), 201-207.

Greco, S., Holmes, M., \& McKenzie, J. (2015). Friendship and happiness from a sociological perspective. In Demir, M (ed.) Friendship and Happiness, 19-35. Springer, Dordrecht.

Helm, B. W. (2009). Friendship. In E. N. Zalta (ed.), The Stanford Encyclopaedia of Philosophy (Fall 2009 Edition). Retrieved from http://plato. stanford.edu/archives/fall2009/entries/friendship/.

Hojjat, M., Moyer, A., \& Halpin, A. M. (eds.). (2017). The Psychology of Friendship. Oxford University Press.

Huesmann, L. R. (2007). The impact of electronic media violence: Scientific theory and research. Journal of Adolescent Health, 41(6), S6-S13.

Jeske, D. (2019). Friendship and Social Media: A Philosophical Exploration. Routledge.

Johnson, H., Lavesson, N., Zhao, H., \& Wu, S. F. (2011). On the concept of trust in online social networks. In L. Salgarelli, G. Bianchi, \& N. Blefari-Melazzi (eds.), Trustworthy Internet. Springer, 143-157.

Laas, O. (2018). Questioning the virtual friendship debate: Fuzzy analogical arguments from classification and definition. Argumentation, 32, 99-149.

Leibowitz, U. D. (2018). What is Friendship? Disputatio, 10(49), 97-117.

Marston, H. R., Musselwhite, C., \& Hadley, R. A. (2020). COVID-19 vs Social Isolation: The impact technology can have on communities, social connections and citizens. British Society of Gerontology-Ageing Issues. Retrieved from https://ageingissues.wordpress.com/2020/03/18/covid-19-vs-social-isolation-the-impact-technology-can-have-oncommunities-social-connections-and-citizens/

McFall, M. T. (2012). Real character-friends: Aristotelian friendship, living together, and technology. Ethics and Information Technology, 14(3), 221-230.

Munn, N. (2012). The reality of friendship within immersive virtual worlds. Ethics and Information Technology, 14(1), $1-10$.

Munn, N. (2017). Friendship and modern life. In T. Shackelford \& V. Weekes-Shackelford (eds.), Encyclopedia of Evolutionary Psychological Science. Springer.

Nehamas, A. (2016). On Friendship. New York, Basic Books.

Nussbaum, M. (1995). Human capabilities, female human beings. In M. C. Nussbaum \& J. Glover (eds.), Women, Culture and Development: A Study of Human Capabilities. Oxford University Press, 61-104.

Nuzzo, R. (2015). Fooling ourselves. Nature, 526(7572), 182.

Rawlins, W. K. (2016). Foreword. In A. Moyer \& M. Hojjatt (eds.), The Psychology of Friendship. New York: Oxford University Press, ix-xiv.

Schønning, V., Hjetland, G. J., Aarø, L. E. and Skogen, J. C., 2020. Social media use and mental health and well-being among adolescents-A scoping review. Frontiers in Psychology, 11, 1949.

Sharp, R. (2012). The obstacles against reaching the highest level of Aristotelian friendship online. Ethics and Information Technology, 14(3), 231-239.

Sherman, N., (1987). Aristotle on Friendship and the Shared Life. Philosophy \& Phenomenological Research, 47: 589-613.

Telfer, E. (1970). Friendship. Proceedings of the Aristotelian Society, 71, 223-241.

Thomas, L., (1987). Friendship. Synthese, 72: 217-36.

Turner, R. N., Hewstone, M., Voci, A., Paolini, S., \& Christ, O. (2007). Reducing prejudice via direct and extended cross-group friendship. European Review of Social Psychology, 18(1), 212-255.

Turp, M.-J. (2020). Social media, interpersonal relations and the objective attitude. Ethics \& Information Technology, 22, 269-279.

Vezzali, L., Hewstone, M., Capozza, D., Giovannini, D., \& Wölfer, R. (2014). Improving intergroup relations with extended and vicarious forms of indirect contact. European Review of Social Psychology, 25(1), 314-389.

White, K. (2018). Touch: Attachment and the Body. Routledge. 